\title{
Direct use of spent mushroom substrate from Pleurotus pulmonarius as a readily delignified feedstock for cellulase production
}

\begin{abstract}
The feasibility of spent mushroom substrate (SMS) as an alternative fermentation feedstock for cellulase production has been demonstrated in this work. Utilization of SMS as a substrate has been attempted widely due to its high cellulose content and readily available in smaller particle size. On top of that, the availability of delignified SMS by the action of Pleurotus pulmonarius during mushroom cultivation offers another benefit to its use whereby no chemical pretreatment would be required prior to fermentation. The recovery of crude laccase and manganese peroxidase from delignified SMS were found to be 3 and $1.4 \mathrm{U} / \mathrm{g}$, respectively. Further to this, the cellulase production from SMS by Trichoderma asperellum UPM 1 under solid state fermentation was optimized by applying central composite design, resulted in increment of 1.4-fold in CMCase $(171.21 \mathrm{U} / \mathrm{g})$ and 1.5 -fold in $\beta$-glucosidase $(6.83 \mathrm{U} / \mathrm{g})$, with the optimum temperature of $27.5{ }^{\circ} \mathrm{C}$, initial moisture content $81 \%$ and initial $\mathrm{pH}$ of fermentation 4.5. Therefore, this study showed that the direct utilization of SMS is feasible for promising cellulase production by T. asperellum UPM 1.
\end{abstract}

Keyword: Cellulase; Bioconversion; Lignocellulolytic enzyme; Filamentaous fungi; Spent mushroom substrate; Solid state fermentation 